\title{
A Detailed Examination of the Enterprise Architecture Frameworks Being Implemented in Pakistan
}

\author{
Hareem Qazi \\ Department of Computer Science, Institute of Business Administration (IBA), Karachi, Pakistan \\ Email: hareem.qazi@khi.iba.edu.pk \\ Zainab Javed \\ Department of Computer Science, Institute of Business Administration (IBA), Karachi, Pakistan \\ Email: zjaved@khi.iba.edu.pk \\ Sameen Majid \\ Department of Computer Science, Institute of Business Administration (IBA), Karachi, Pakistan \\ Email: sameen.majid@khi.iba.edu.pk \\ Waqas Mahmood \\ Department of Computer Science, Institute of Business Administration (IBA), Karachi, Pakistan \\ Email: wmehmood@iba.edu.pk
}

Received: 29 May 2019; Accepted: 14 August 2019; Published: 08 September 2019

\begin{abstract}
Managing the underlying structure of an enterprise is a daunting task. The business management and IT management alike have to deal with intricate layers of complexity that lies beneath the surface of the day-to-day operations of an enterprise. Without a proper Enterprise Architecture Framework, any organization regardless of size and magnitude of operations is bound to struggle in managing their business strategies. However, choosing a suitable Enterprise Architecture Framework is in itself a pretty hard endeavor that requires a deep dive into the terrifying maze of available Enterprise Architecture Frameworks and their respective characteristics. In this study, we compare the major Enterprise Architecture Frameworks that are currently prevalent in Pakistan. Through a well-crafted questionnaire we conducted a survey and assessed what Enterprise Architecture Frameworks most of the industries in Pakistan are using and the enterprise's level of satisfaction with the achieved results. By focusing on the trends of Enterprise Architecture Framework implementation in Pakistan we try to offer a unique perspective on the comparative studies of Enterprise Architecture Framework that are usually done on general basis.
\end{abstract}

Index Terms-Enterprise Architecture Frameworks, Enterprise Architecture, TOGAF, Zachman, MODAF, FEAF, DoDAF

\section{INTRODUCTION}

The recent era of globalization has witnessed organizations facing immense competition and several of them are even struggling for survival. Now more than ever, organizations are focusing on refining their business process to remain relevant in the industry and to serve their clients effectively and efficiently [1]. Implementation of Enterprise Architecture frameworks within an organization is one of the ways to ensure effective and consistent flow of a business process for improved performances. Enterprise Architecture is a well-defined and established practice that enables to structure the logic of a business process and ensures successful implementation of an enterprise by conducting each phase of enterprise development comprehensively. The development of an enterprise includes the analysis, design, implementation and effective execution [2]. Numerous architectural frameworks are being used by companies considering the nature of their business and the ideologies they believe in. Enterprise Architecture framework provides organizations the opportunity to appropriately utilize their resources and achieve optimal results with minimum effort and cost. The decision of selecting and implementing any specific EA framework depends on the concerned stakeholders (internal and external) responsible for determining how the business of the organization gets carried out. 
The motivation behind this research paper is to present a comparative analysis of different architecture frameworks of an enterprise like The Zachman Framework, The Open Group Architecture Framework (TOGAF), Service Oriented Architecture (SOA), The Department of Defence Architecture Framework (DoDAF), The British Ministry of Defence Architecture Framework (MODAF), The Federal Enterprise Architecture Framework (FEAF), The NATO Architecture Framework (NAF). This paper aims to discuss and analyze how Enterprise Architecture Frameworks (EAFs) help in integrating different applications of an enterprise by reducing complexity of business processes. Significant elements of each framework will be highlighted to aid organizations while selecting a framework to implement. A survey is conducted aiming to deduce the most preferred Enterprise Architecture Framework depending upon the domain and size of the company. Participants were asked whether the applied framework improved overall performance of the organization and whether the implementation was worth the cost and effort. Through the results of the survey, different organizations will be able to use this study as a one stop guide for selecting a suitable Enterprise Architecture framework that satisfies and cater to their organization's unique needs. It will also help them in devising and implementing better IT policies and IT governance, enhancing the effectiveness and proficiency of their business process and routine activities.

This research paper comprises of total six sections. In this section we have provided the introduction and aim of the paper. Section II consists of background and brief history of enterprise architecture frameworks and their implementation. Literature review is conducted in Section III that discusses the past studies conducted on various EA frameworks. Section IV describes the details of methodology adopted to carry out the study. In Section V, the results and analysis of the survey has been discussed and we have also compared the results of our study with a study previously conducted on a similar topic. Section VI finalizes the paper by presenting the conclusion of the study.

\section{BACKGROUND}

Enterprise architecture represents the interrelationship between IT systems and enterprise's business processes and specifies the goal and target that should be achieved by an organization [3]. It also serves as a framework to facilitate the integration among different applications and describes the significant long-term vision of an enterprise. IEEE Standard 1471 defines architecture as "the fundamental organization of a system embodied in its components, their relationships to each other, and to the environment, and the principle guiding its design and evolution" [4]. Some of the main objectives of an enterprise architecture (EA) are improved decision making and responsiveness, better collaboration and communication, reduced costs, and to plan an effective alignment of business and IT [3].
Enterprise Integration (EI) refers to as a technology that can be used to streamline the processes and business functions in silos and ensures the flexibility and agility of an enterprise. The uses and benefits of EA were proposed by the Enterprise Integration Council that can be implemented to reduce and manage the complexity of an organization [5].

\section{RELATED WORK}

This section presents an overview of literature conducted by various researchers in the field of Enterprise Architecture (EA) and its frameworks. EA Frameworks are usually compared by researchers on general basis. In light of this fact, a study was made where different Enterprise Architecture Frameworks (EAF) were compared based on quality attributes of Enterprise Architecture to get a better idea of how they compete against each other in the race of providing actual business value [6]. Objective attributes were defined such as interoperability, reusability, scalability, etc. to assess the Enterprise Architecture Framework quality. A fourdimensional criterion consisting of concepts: Time, scope, view and perspective was used to categorize the quality attributes. Two combined framework and three descriptive frameworks were then compared on the basis of criteria like decoupling and integration capability. It was concluded through this research that no single framework can satisfy all the quality attributes and the architect must clear-fully configure an EAF to meet the required quality standards.

A survey based research focusing on analyzing how EA Frameworks are being used in organizations using quantitative data and to figure out whether EAF is beneficial in aligning the goals of IT and business was conducted [7]. As mentioned above [6], this research also points out the importance of quality attributes and how they are related to each other. The findings of this research have established an alarming notion that many companies do not have the capability to prioritize the desired qualities from an Enterprise Architecture framework. The authors have stressed on the importance of better prioritization on successfully implementing any EA Framework. By comparing three of the most widely used EA Frameworks, this research paper tried to figure out if it was possible to design a single and standardized framework that merges the common benefits of each of the individual framework [8].

Donaldson, Blackburn, Blessner, and Olson [9] discussed various constraints that occur during the implementation of Enterprise Architecture Framework and also suggested the enhancements that can play a vital role in the transformation of an enterprise. In the first part of the paper, different factors are identified that lead towards the failure of EAF execution. The paper identified lack of collaboration between enterprise architects and business management as one of the main reasons of failure. Research survey was conducted in the second part to obtain visibility and to ensure improvement in the application process of EAFs. 
Buckl [10] presented and discussed the utilization of The Open Group Architecture Framework (TOGAF) to manage all processes in an enterprise using implementation of ten phases of Architecture Development Method (ADM). To address commonly existing issues of architectures, an Enterprise Architecture Management (EAM) pattern-based approach can be used along with ADM to improve the results. Scherer and Wimmer [11] analyzed and suggested that implementing EA frameworks can help in effective development and implementation of an e-participation project. The Zachman Framework was recommended for Initiation and Design phases while TOGAF was considered appropriate for project implementation phase. The analysis was carried out by first identifying the key aspects of an e-participation project and then comparing the main viewpoints, foundational structure and procedural model of the selected frameworks.

A meta framework was proposed called EA Framework Framework $\left(\mathrm{EAF}^{2}\right)$ aiming to help CIOs and key stakeholders in selecting the most appropriate framework for the organization [12]. Furthermore, the meta framework intended to aid standardization committees in developing frameworks for diverse industries. Almost seven of the most popularly adopted frameworks were selected and their unique features were identified and compared. The $\mathrm{EAF}^{2}$ was divided in two classes, Architecture Governance (stating the management related issues of an EA) and Modeling Concept (definitions and formal implementation guidelines for actual models). $\mathrm{EAF}^{2}$ provided a platform to compare and analyze different EA frameworks, simplifying the decision-making process.

A research paper "Enterprise Architecture Frameworks" published in 2007, discussed EA frameworks and implementation challenges thoroughly. It emphasized that stakeholders of the organization should be informed about the systems and architectures required for carrying out operations effectively. The paper highlighted the importance of Enterprise Architecture as it accommodates in connecting multiple lines of business and facilitates enterprises to utilize software as a service. Enterprise Architecture enables to structure the organizational data thus resulting in effective resource planning, budget planning, and better process and schedule management [13]. Most of the time employees aren't even aware of the existence of enterprise architecture within their organization and even if they are, they tend to avoid following it and cause massive hurdle in company's performance. This challenge highlights that people in management, IT and other key departments need to collaborate and communicate their concerns.

Rouhani [14] has put forward a framework to assess different Enterprise Architecture Implementation Methodologies. The evaluation framework uses three major characteristics of an EAIM like Concepts, Modeling and Process. According to the results of this research, no single methodology was able to meet all the demands of an effective EA implementation as per the proposed framework, however TOGAF had the highest rating when compared to others. The researchers also emphasized on the need to consider the issue that most of the leading EAIMs don't provide ample maintenance.

\section{A. Enterprise Architecture Frameworks (EAFs)}

Business, organization, technology and information are the four fundamental domains of an enterprise architecture (EA). EA framework presents an approach to structure and systematically develop and manage the information system models of an enterprise [15]. As shown in Table 1, author Tang et al. compared six architecture frameworks and analyze different perspective and viewpoints of architecture models.

Table 1. Comparison of Enterprise Architecture Frameworks [15]

\begin{tabular}{|c|c|c|}
\hline $\begin{array}{l}\text { Sr. } \\
\text { No. }\end{array}$ & $\begin{array}{l}\text { Architecture } \\
\text { Frameworks }\end{array}$ & Description \\
\hline 1. & $\begin{array}{l}\text { Zachman Framework } \\
(\mathrm{ZF})\end{array}$ & $\begin{array}{l}\text { The main idea behind ZF is to } \\
\text { develop and design an information } \\
\text { system by analyzing the enterprise } \\
\text { architecture and to model and } \\
\text { structure its system. The outcome of } \\
\text { ZF process is not detailed and does } \\
\text { not determine the support for non- } \\
\text { functional requirements. }\end{array}$ \\
\hline 2. & 4+1 View Model & $\begin{array}{l}\text { This model recommends a recurring } \\
\text { approach to deal with the complexity } \\
\text { of a system. It proposes the } \\
\text { architecture of an enterprise in terms } \\
\text { of four viewpoints (logical view, } \\
\text { physical view, development view } \\
\text { and process view) and }+1 \text { indicates } \\
\text { the view of scenarios to discover and } \\
\text { verify the design of a software } \\
\text { systems. }\end{array}$ \\
\hline 3. & $\begin{array}{l}\text { Federal Enterprise } \\
\text { Architecture } \\
\text { Framework (FEAF) }\end{array}$ & $\begin{array}{l}\text { The primary purpose of FEAF is to } \\
\text { plan the organization's architecture. } \\
\text { As inputs for architecture planning, } \\
\text { FEAF uses business drivers, design } \\
\text { drivers and architecture drivers. }\end{array}$ \\
\hline 4. & $\begin{array}{l}\text { Reference Model - } \\
\text { Open Distributed } \\
\text { Processing (RM - } \\
\text { ODP) }\end{array}$ & $\begin{array}{l}\text { RM - ODP targets on the } \\
\text { development of open distributed } \\
\text { processing (ODP) architecture. It's } \\
\text { considered as a formal framework } \\
\text { which produces complete } \\
\text { specification of the model to design } \\
\text { an enterprise architecture. }\end{array}$ \\
\hline 5. & $\begin{array}{l}\text { The Open Group } \\
\text { Architecture } \\
\text { Framework } \\
\text { (TOGAF) }\end{array}$ & $\begin{array}{l}\text { TOGAF focuses on the process of } \\
\text { development and evolution of the } \\
\text { architecture adopted by organization. } \\
\text { Architecture Development Method } \\
\text { (ADM) is the basic element of } \\
\text { TOGAF. It recommends } \\
\text { comprehensive methodology along } \\
\text { with design rationale documentation. }\end{array}$ \\
\hline 6. & $\begin{array}{l}\text { Department of } \\
\text { Defense Architecture } \\
\text { Framework } \\
\text { (DoDAF) }\end{array}$ & $\begin{array}{l}\text { DoDAF uses Core Architecture Data } \\
\text { Model (CADM) to define and } \\
\text { describe the operations of } \\
\text { organization's business process and } \\
\text { different elements of a database. }\end{array}$ \\
\hline
\end{tabular}

In literature, following Enterprise Architecture Frameworks (EAFs) have been examined to facilitate various organization in development of a successful IT infrastructure.

a. Service-Oriented Architecture (SOA) 
Chindove et al. [16] discussed the relationship between Service-Oriented Architecture (SOA) and enterprise architecture (EA) and their organizational benefits. SOA assures the agility and alignment of business operations by providing its services for the development of desired architecture. EA helps to interpret SOA and provides the structured perspective of IT and business. EA and SOA both share the same goals for an enterprise's success. The role of SOA in the development of EA is considered vital, as both ensures improved learning, continuous collaboration and increased reusability of opportunities. Van Belle et al. [17] investigated SOA adoption in South Africa in his survey paper. Authors addressed the impact of SOA on an organization that enhances the interoperability and adaptability of systems and suggested that SOA can be implemented by all small or large organizations. Security, complexity and cost are some of the key factors that may negatively impact successful implementation of SOA.

\section{b. DoDAF}

The Department of Defense Architecture Framework (DoDAF) assists organizations to understand, visualize and define the problems efficiently [18]. According to Amissah and Handley [19], DoDAF facilitates data sharing based on the template of conceptual models and XML. A framework was proposed in the paper known as Data-Centric Architecture Modeling (DCAM) that aligns with the paradigm of DoDAF. It serves the community of US defense by developing and managing the architecture of various systems.

\section{c. Zachman Framework}

The Zachman Framework is often considered as a schema or an ontology that models the different parts of an organization [20]. It's basically a square matrix of dimensions of six rows and six columns. The columns denote the essentials of communication, particularly the 'how', and the five W-questions. These questions are basically termed as Zachman interrogatives. The rows of the matrix are called Zachman perspectives where the different perspectives of an enterprise are modeled through the viewpoints of various stakeholders like the engineers, architects, management and technician, etc.

\section{d. The Open Gate Architecture Framework (TOGAF)}

Through an exploratory research, a brief study was put forward that covers the major aspects of a TOGAF-based enterprise architecture [21]. It is widely believed and is constantly asserted by the Open Group that TOGAF is the most commonly used EAF in the major corporations of the world. It is composed of two major components: Architecture Development Method and Architecture Content Framework. TOGAF offers an effective way to design the Enterprise Architecture through a 5-step method that includes recording the present state of the system, documenting the required future condition, figuring out the current shortcomings, coming up with a comprehensive plan, and then finally executing the said plan.

\section{e. FEAF}

The Federal Enterprise Architecture Framework (FEAF) was designed for the sole purpose of establishing the tradition of implementing Enterprise Architecture in federal organizations [22]. The CIO Council in the US originated the first and formal EAF which came to be known as The Federal Enterprise Architecture Framework. FEAF puts major emphasis on all the aspects of an enterprise that deals with aligning technical and business goals. Furthermore, FEAF focuses on building a strong IT foundation for any organization that eventually helps in the development of an efficient IT-business strategy.

\section{f. MODAF and NAF}

A study was conducted on the implementation of EA framework in application consolidation project by armed forces of Sweden [23]. Decision theory was formed by analyzing the problem and possible interoperability issues. Ministry of Defence Architecture Framework (MODAF) was proposed as the ideal framework, as it enables to provide consistency, transparency, maintainability and well-formed structure. The consolidation project proved to be complex as shifting a large-scale application towards service orientation is quite hard. The implementation of MODAF helped in making the process efficient and providing a structured platform to document and transform the application to its desired form.

A research study in 2011 presented the experience of combining and integrating TOGAF and NAF for Norwegian Armed Forces [24]. The strength and drawbacks of each framework were analyzed while customizing frameworks to provide a sustainable model. The study observes that NAF enables visualizing the technical characteristics of an Enterprise Architecture implemented currently, which helps military organizations to plan their future works accordingly. The study describes four architectures of NAF proposed by NATO that helps in addressing the future of an organization, how the organization operates and the possible tools for developing. The integration process required focus as both frameworks have different stances on enterprise architectures and information systems. TOGAF differed in Architecture layers whereas NAF proposed different detailing in baselines and targets thus making the entire integration process more challenging than anticipated.

\section{METHODOLOGY}

An online survey was conducted to gain insight about the current surge in organizations to implement frameworks, and their satisfaction after successfully implementing an adequate EA Frameworks based on company's specific needs. Google form was used to design the survey for professionals working in organizations in Pakistan. The questionnaire comprised 
of questions related to the different EA Frameworks adopted by organizations, and the motivation behind adopting them. The survey also aimed to highlight the widely adopted Enterprise Architecture Frameworks in organizations belonging from different domains. Few questions included in the survey were adopted by previous studies in the papers 'Analyzing the Current Trends in Enterprise Architecture Frameworks' [18] and 'A Comparison of Enterprise Architecture Frameworks' [25]. The adopted questions were customized and edited catering to our target audience. We were able to collect only 91 responses due to the general lack of awareness of EA frameworks.

\section{RESULTS AND ANALYSIS}

According to the online survey conducted for this research paper, approximately $22 \%$ respondents are from banking and financial sector, $16.5 \%$ are working in energy and utilities sector and $15.4 \%$ of the respondents are from Information Technology (IT) industry as shown in Fig. 1.

91 responses

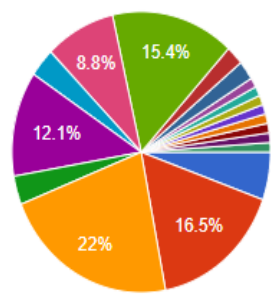

- Government - State and Local - Energy and Utilities Banking and Financial - Government/Federal, Defense//ntell... - Information Technology Secto Insurance - Education Information Technology $\Delta 1 / 3 \mathbf{V}$

Fig.1. What is your Organization's primary domain of Operation?

As shown in Fig. 2, the organizations of $60.7 \%$ respondents are not multinational whereas approximately $39.3 \%$ people are working in multinational organizations.

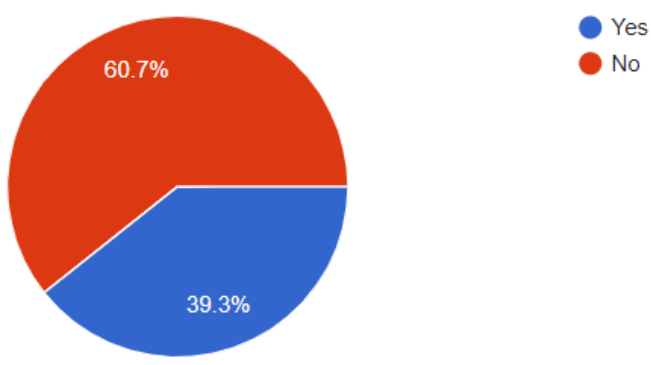

Fig.2. Is your Organization a Multinational Corporation?

The survey results in Fig. 3, depict that approximately $35.2 \%$ of the organizations have more than 100 employees in the department of IT whereas $29.7 \%$ of the organizations consist of considerably small number of IT employees i.e. less than 25. According to survey results,
$18.7 \%$ of the respondents' organizations have 50-100 number of IT professionals.
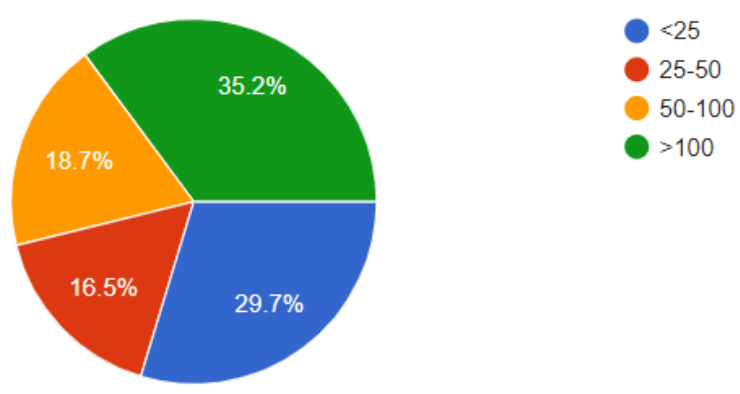

Fig.3. What is the number of IT Employees in your Organization?

As shown in Fig. 4, it is evident from the responses that approximately $33 \%$ of the organizations have implemented the Service-Oriented Architecture (SOA). The second most adopted framework is TOGAF which is implemented by $26.4 \%$ of the organizations, followed by Zachman framework. According to $5 \%$ of the respondents, either no framework is used in their organizations or they don't have any about it.

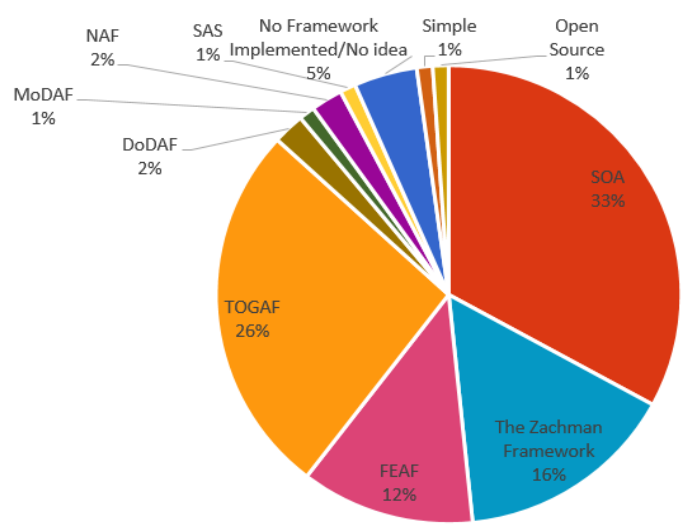

Fig.4. Which of the following Enterprise Architecture Framework has been implemented in your organization?

According to $48.4 \%$ of the respondents, an implementation of the chosen enterprise architecture (EA) did not prove to be a difficult job. There are few EA frameworks that offers a comprehensive methodology and therefore requires more time and preparation for implementation. As it can be seen from the results below (Fig. 5.), 27.5\% of the respondents' organizations found EA framework implementation challenging.

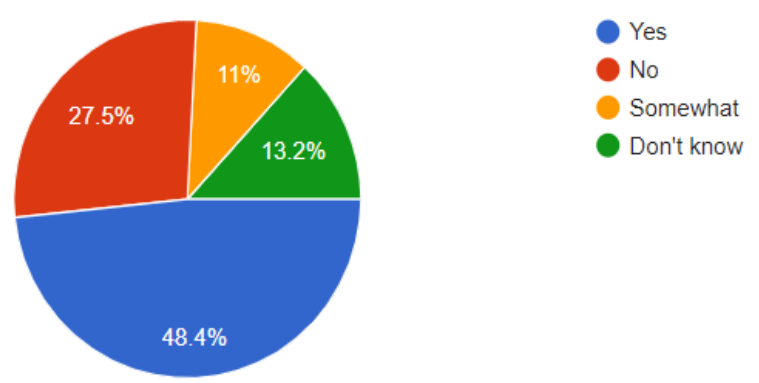

Fig.5. Was the chosen EA Framework easy to implement? 
In Fig. 6, according to $39.6 \%$ respondents, their organizations have hired external enterprise architects for the implementation of EA program whereas $35.2 \%$ organizations have internal Enterprise Architects.

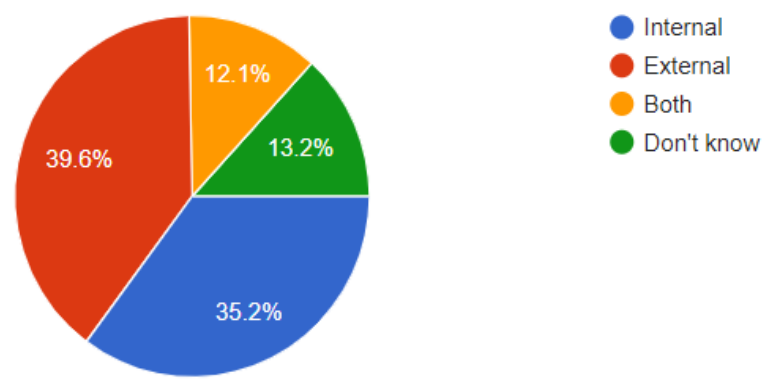

Fig.6. What type of Enterprise Architects does your organization have?

According to respondents, approximately $29.7 \%$ of the organizations have initiated Enterprise Architecture (EA) Program between 1 to 3 years ago. $26.4 \%$ of the respondents said their organizations have implemented EA program 3 to 6 years ago formally, as shown in Fig. 7.
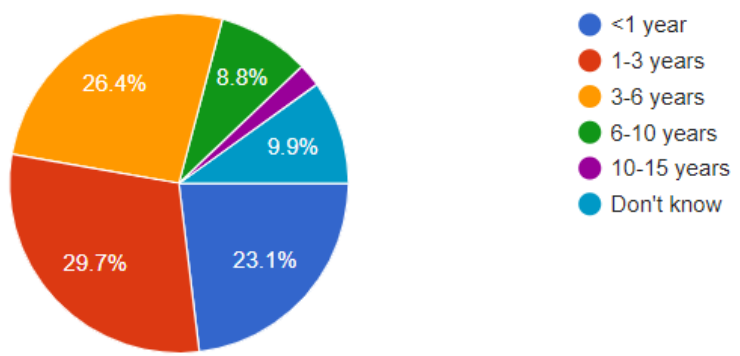

Fig.7. How long has your Organization had a Formal Enterprise Architecture (EA) Program?

As the trend is showing in Fig. 8, the top-most reasons for choosing and implementing enterprise architectures are the clear process of development and ease-of-use in carrying out the business operations. According to $51 \%$ respondents, their organization wanted structured and consistent model followed by $51.6 \%$ of the respondents who stated a clear process of development was the main motivation behind implementing a framework. Survey showed that $50.5 \%$ people believed ease of use as the essential reason for EAF whereas $49.5 \%$ believed that business strategy-driven approach was also the main criteria for adopting it.

Results in Fig. 9, shows that approximately $38.5 \%$ of the organizations adopted EA frameworks that are widely used and are popular. According to $22 \%$ of the respondents they use the hybrid framework approach. $14.3 \%$ of the respondents did not know which type of framework approach was implemented in their organization.

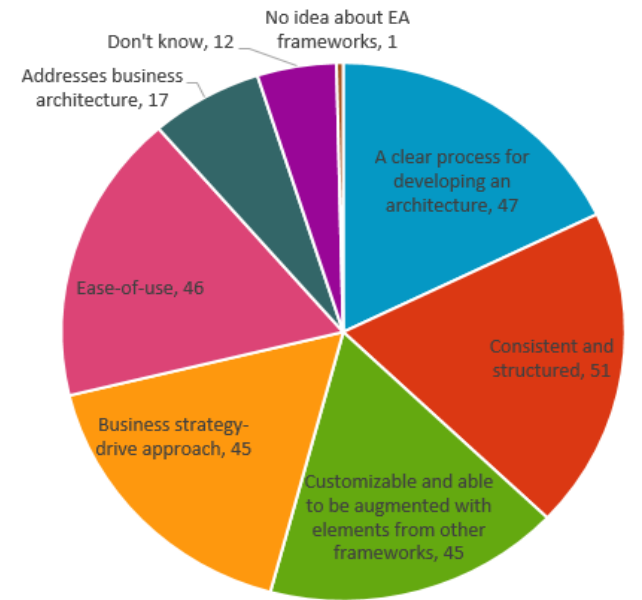

Fig.8. What was the criteria for choosing/developing an EA Framework?

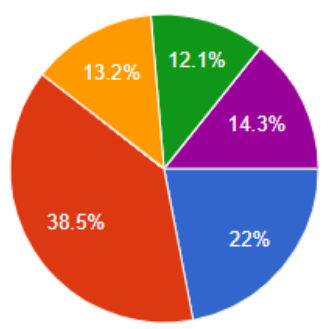

Hybrid framework

- Popular EA framework

Original EA framework

Consulting firm framework

Don't know

Fig.9. Which of the Following Best Describes your Organization's EA Framework Approach?

The below survey results as shown in Fig. 10, depict that one of the main benefits of implementing an EA program is the improvement in the alignment between business and IT governance. Enterprise architecture framework improves business efficiency and makes System Integration easy. According to most of the respondents, operating costs also reduces significantly due to the implementation of EA frameworks.

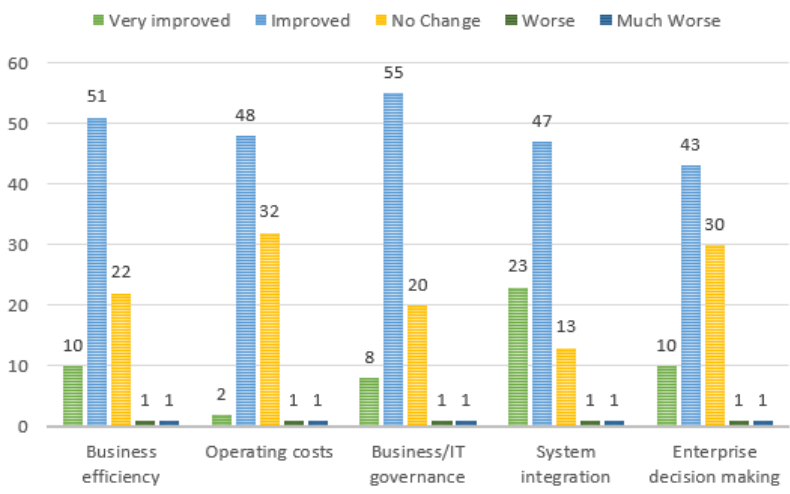

Fig.10. As the result of the EA program, how has the following improved (or is improving)?

As shown in Fig. 11, 45.1\% of the respondents said that the chosen framework has helped the organizations in achieving all the goals and objectives they had intended by implementing EA program while the same percentage of respondents is neutral in this prospect. 


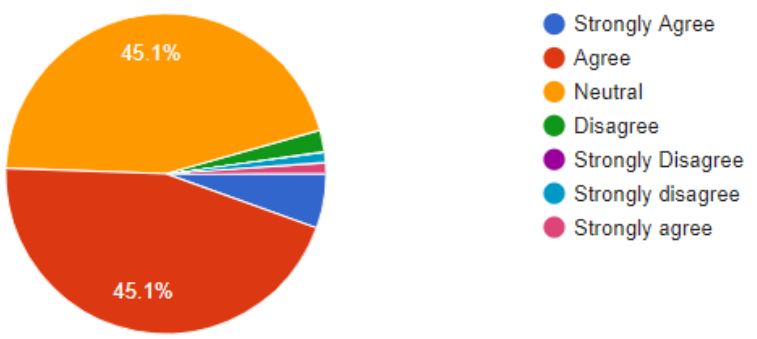

Fig.11. Has the chosen EA Framework has helped the Organization in achieving all the goals it had intended to fulfill with EA program?

As shown in Fig. 12, more than half of the respondents i.e. approximately $59.3 \%$ were neutral about the involvement of entire Software Development Lifecycle (SDLC) during the process of an implementation of chosen Enterprise Architecture Framework (EAF).
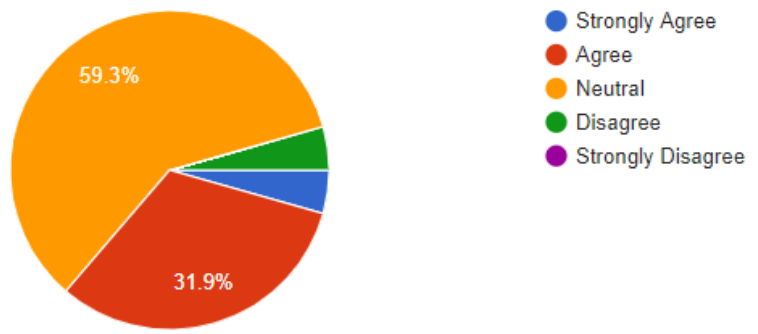

Fig.12. Does the chosen EA Framework encompass the entire Software Development Life Cycle?

EA Framework provides efficient and cost-effective solution to different organizations. From the results of Fig. $13,45.1 \%$ of the respondents were neutral about the fact that the implemented EA framework provides good value for money. $40.7 \%$ of the respondents were satisfied with the value and cost trade-off of the implemented EA framework.

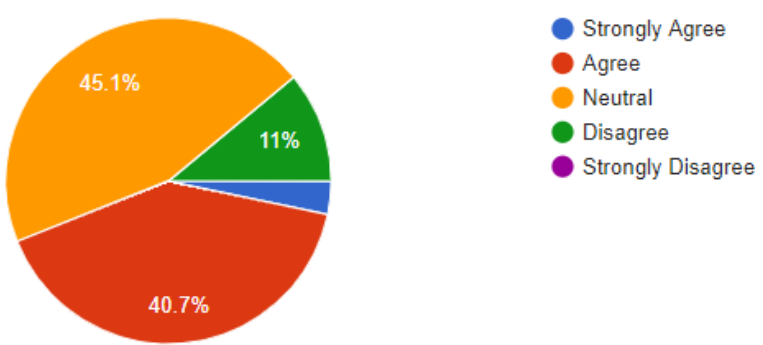

Fig.13. The EA Framework implementation and maintenance cost was under your budget and provided good value for the money?

In Fig. 14, according to $39.6 \%$ audience their organizations took anticipated amount of time to implement the selected enterprise architecture framework.

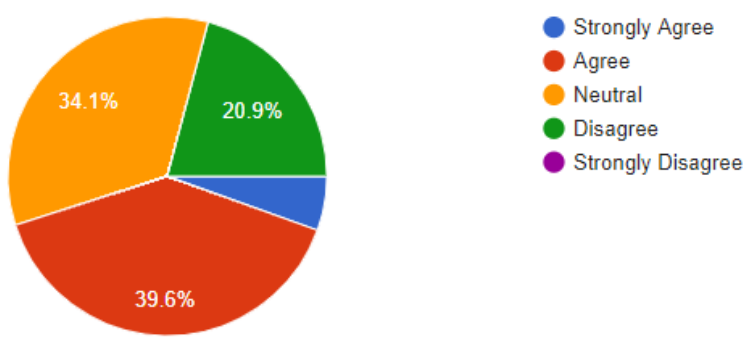

Fig.14. Did the implementation of the chosen framework take the anticipated amount of time?

The core objective of an Enterprise Architecture Framework is to align business and IT management and offers continuous collaboration and improvement. Approximately $47.8 \%$ of the respondents agreed that EAF helps the organizations in achieving desired goals and creates an overall positive impact on performance and productivity of business operations, given in Fig. 15.

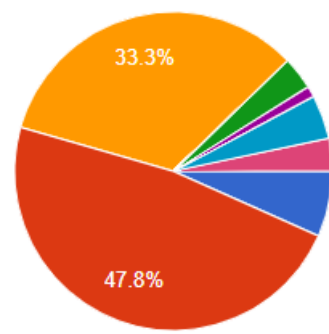

$$
\begin{aligned}
& \text { Strongly Agree } \\
& \text { Agree } \\
& \text { Neutral } \\
& \text { Disagree } \\
& \text { Strongly Disagree } \\
& \text { Strongly agree } \\
& \text { Strongly disagree }
\end{aligned}
$$

Fig.15. With the help of the chosen EA Framework the Organization was able to align the goals of Business Management and Technical Management?

As it can be seen in Fig. 16, 46.2\% of the organizations were able to achieve their needs after the implementation of enterprise architecture framework which may results in cost-reduction and growth in revenue and provides stability to the structure of an enterprise.

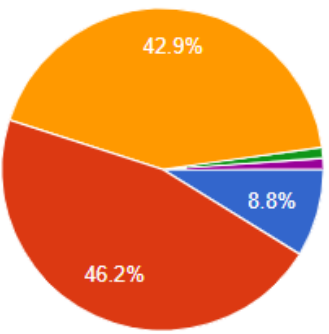

$$
\begin{aligned}
& \text { Strongly Agree } \\
& \text { Agree } \\
& \text { Neutral } \\
& \text { Disagree } \\
& \text { Strongly Disagree }
\end{aligned}
$$

Fig.16. Were the Enterprise Architects able to design an Enterprise Architecture that satisfies your Organization's needs using the EA Framework?

As it can be seen from the survey results of Fig. 17, according to $40.7 \%$ of the respondents it was not an easy task for their organizations to train the staff whereas approximately $33 \%$ said it was easy to train their employees for using EA tools. 


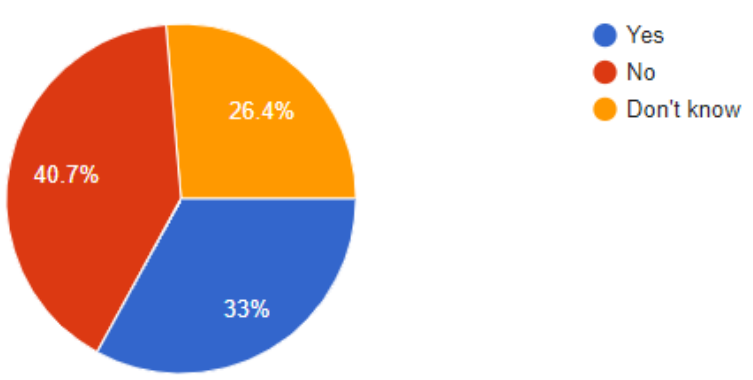

Fig.17. Was it easy to train the staff in using the EA Framework?

As shown in Fig. 18, 57.1\% of the organizations are satisfied and doesn't consider ending the EA program whereas $38.5 \%$ of the respondents were not sure about the outcome of the implemented framework and their organization might have considered ending the EA program in the past.

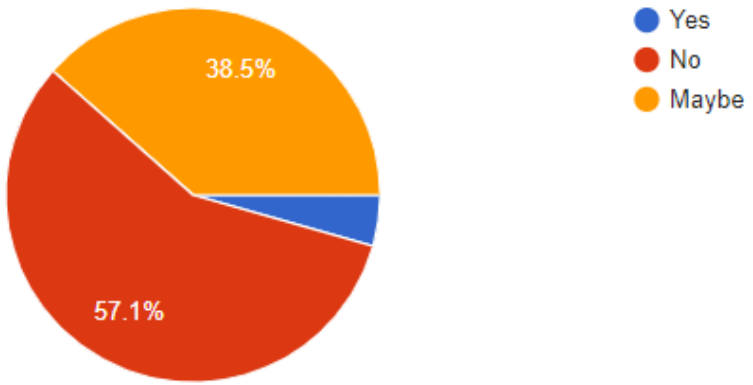

Fig.18. Has your Organization ended or ever considered ending the EA program?

\section{A. Comparative Analysis}

In Table 2, we have presented the results by comparing our research findings to a base paper titled "Analyzing the Current Trends in Enterprise Architecture Frameworks" [18]. Only significant results with higher impact have been listed in the table. The survey findings of the base paper analyzed responses from the total number of 334 people.

Table 2. Comparison between the survey results of this paper with another [18]

\begin{tabular}{|c|c|c|c|}
\hline Sr. No. & Questions & $\begin{array}{l}\text { Comparative Analysis of Enterprise } \\
\text { Architecture Frameworks: A Survey }\end{array}$ & $\begin{array}{l}\text { Analyzing the Current Trends in } \\
\text { Enterprise Architecture Frameworks }\end{array}$ \\
\hline 1. & Industries of the respondents & $\begin{array}{l}\text { Banking and Financial - 22\% } \\
\text { Energy and Utilities }-16.5 \%\end{array}$ & $\begin{array}{l}\text { Government State and Local - 8\% } \\
\text { Energy and Utilities - } 7 \%\end{array}$ \\
\hline 2. & $\begin{array}{l}\text { How long has your } \\
\text { organization had a formal EA } \\
\text { Program? }\end{array}$ & $\begin{array}{l}1-3 \text { years }-29.7 \% \\
3-6 \text { years }-26.4 \%\end{array}$ & $\begin{array}{l}<1 \text { year }-16 \% \\
1-3 \text { years }-32 \%\end{array}$ \\
\hline 3. & $\begin{array}{l}\text { Number of IT Employees in } \\
\text { the Organization }\end{array}$ & $\begin{array}{l}>100-35.2 \% \\
<25-29.7 \%\end{array}$ & $\begin{array}{l}<25-7 \% \\
26-50-3 \%\end{array}$ \\
\hline 4. & $\begin{array}{l}\text { What are the top criteria } \\
\text { identified by your } \\
\text { organization for choosing or } \\
\text { developing their own EA } \\
\text { framework? }\end{array}$ & $\begin{array}{l}\text { Consistent and structured - } 56 \% \\
\text { Clear process for developing an } \\
\text { architecture-51.6\% }\end{array}$ & $\begin{array}{l}\text { Clear process for developing an } \\
\text { architecture }-37 \% \\
\text { Consistent and structured }-27 \%\end{array}$ \\
\hline 5. & $\begin{array}{l}\text { What is the most commonly } \\
\text { adopted EA framework? }\end{array}$ & $\begin{array}{l}\text { SOA - } 33 \% \\
\text { The TOGAF Standard }-26.4 \% \\
\text { Zachman }-15.4 \%\end{array}$ & $\begin{array}{l}\text { The TOGAF Standard - } 20 \% \\
\text { DoDAF - } 2 \% \\
\text { FEAF - > } 1 \%\end{array}$ \\
\hline 6. & $\begin{array}{l}\text { Which of the following best } \\
\text { describes your Organization's } \\
\text { EA Framework Approach? }\end{array}$ & $\begin{array}{l}\text { Popular EA framework - } 38.5 \% \\
\text { Hybrid framework - } 22 \%\end{array}$ & $\begin{array}{l}\text { Hybrid framework - } 54 \% \\
\text { Popular EA framework - } 26 \%\end{array}$ \\
\hline
\end{tabular}

\section{CONCLUSION}

The result of the comparative analysis of widely adopted Enterprise architecture framework suggests that each framework has different and unique compatibility requirements and can only be considered profitable if implemented appropriately. An adequate EA Framework carries the ability to reshape the future of the company, thus it is vital for organizations to implement a framework that will help in meeting the business objectives and desired goals. The survey conducted for the paper helped in highlighting extensively implemented frameworks in different fields. TOGAF and Zachman stood out as the popular choice for IT, Banking and Utility sector while SOA also came out as the most implemented option in various fields. Due to the limited audience, clear usage of MODAF, NATO Framework, DoDAF, FEAF could not be analyzed. The survey results also pointed out the lack of knowledge of professionals about the EA framework and how profitable it could be to implement one. Organizations must make conscious efforts to promote the benefits and proper use of EA Frameworks to ensure that they are gaining maximum profits through its implementation.

\section{REFERENCES}

[1] O. A. Adenuga and R. M. Kekwaletswe, "Towards a Framework for a Unified Enterprise," Int J Comput Inf Technol, vol. 3, no. 2, pp. 30-33, 2012.

[2] W. contributors, "Enterprise architecture," [Online]. Available:

https://en.wikipedia.org/w/index.php?title=Enterprise_arc hitecture\&oldid=891796709. [Accessed 16 April 2019]. 
[3] T. Tamm, P. B. Seddon, G. Shanks and P. Reynolds, "How Does Enterprise Architecture Add Value to Organisations?," Communications of the Association for Information Systems, vol. 28, no. 1, p. 10, March 2011.

[4] H. Jonkers, M. M. Lankhorst, H. W. t. Doest, F. Arbab, H. Bosma and R. J. Wieringa, "Enterprise architecture: Management tool and blueprint for the organisation," Information Systems Frontier, vol. 8, no. 2, pp. 63-66, 2006.

[5] N. Banaeianjahromi and K. Smolander, "What do we know about the role of enterprise architecture in enterprise integration? A systematic mapping study," Journal of Enterprise Information Management, vol. 29, no. 1, pp. 140-164, 2016.

[6] N. Lim, T.-G. Lee and S.-G. Park, "A Comparative Analysis of Enterprise Architecture Frameworks based on EA Quality Attributes," in 2009 10th ACIS International Conference on Software Engineering, Artificial Intelligences, Networking and Parallel/Distributed Computing, 2009.

[7] U. Franke, M. Ekstedt, R. Lagerström and J. S. Winter, "Trends in Enterprise Architecture Practice - A Survey," in International Workshop on Trends in Enterprise Architecture Research, 2010.

[8] R. Mccarthy, "Toward a unified enterprise architecture framework: An analytical evaluation.," Issues in Information Systems., vol. 7, no. 2, pp. 14-17, 2019.

[9] W. M. Donaldson, T. D. Blackburn, P. Blessner and B. A. Olson, "An Examination of the Role of Enterprise Architecture Frameworks in Enterprise Transformation," Journal of Enterprise Transformation, vol. 5, no. 3, pp. 218-240, 2015.

[10] S. Buckl, A. M. Ernst, F. Matthes, R. Ramacher and C. M. Schweda, "Using enterprise architecture management patterns to complement TOGAF," in International Enterprise Distributed Object Computing Conference, 2009.

[11] S. Scherer and M. A. Wimmer, "E-participation and enterprise architecture frameworks: An analysis.," Information Polity, vol. 17, no. 2, pp. 147-161, 2012.

[12] U. Franke, D. Hook, J. Konig, R. Lagerstrom, P. Narman, J. Ullberg, P. Gustafsson and M. Ekstedt, "A Framework for Categorizing Enterprise Architecture Frameworks," in 10th ACIS International Conference on Software Engineering, Artificial Intelligences, Networking and Parallel/Distributed Computing, 2009.

[13] H. Shah and M. E. Kourdi, "Frameworks for enterprise architecture," It Professional, vol. 9, no. 5, pp. 36-41, September 2007.

[14] B. D. Rouhani, M. N. Mahrin, F. Nikpay and P. Nikfard, "A Comparison Enterprise Architecture Implementation Methodologies," in 2013 International Conference on Informatics and Creative Multimedia, Kuala Lumpur, 2013.

[15] A. Tang, J. Han and P. Chen , "A Comparative Analysis of Architecture Frameworks," in Proceedings of the 11th Asia-Pacific Software Engineering Conference (APSEC'04), 2004.

[16] H. Chindove, L. F. Seymour and F. I. v. d. Merwe, "Service-oriented Architecture: Describing Benefits from an Organisational and Enterprise Architecture Perspective," in In Proceedings of the 19th International Conference on Enterprise Information Systems (ICEIS 2017), 2017.
[17] J. P. Van Belle and E. MacLennan, "Factors Affecting the Organizational Adoption of Service-Oriented Architecture (SOA)," Information Systems and e-Business Management, vol. 12, no. 1, pp. 71-100, 2014.

[18] B. H. Cameron and E. McMillan, "Analyzing the Current Trends in Enterprise Architecture Frameworks," Journal of Enterprise Architecture, vol. 9, no. 1, pp. 60-71, 2013.

[19] M. Amissah and P. P. Holly A. H. Handley, "A Process for DoDAF Based Systems Architecting," in Annual IEEE Systems Conference (SysCon), 2016.

[20] J. Lapalme, A. Gerber, A. Van der Merwe, J. Zachman, M. De Vries and K. Hinkelmann, "Exploring the future of enterprise architecture: A Zachman perspective," Computers in Industry, vol. 79, pp. 103-113, 2016.

[21] S. Kotusev, "TOGAF-based Enterprise Architecture Practice: An Exploratory Case Study," Communications of the Association for Information Systems, vol. 43, no. 1, pp. 321-359, 2018.

[22] Q. Bui, "Evaluating enterprise architecture frameworks using essential elements," Communications of the Association for Information Systems, vol. 41, no. 1, pp. 121-149, 2017.

[23] U. Franke and P. Johnson, "An enterprise architecture framework for application consolidation in the Swedish Armed Forces.," in 2009 13th Enterprise Distributed Object Computing Conference Workshops, 2009.

[24] H. D. Jørgensen, T. Liland and S. Skogvold, "Aligning TOGAF and NAF - Experiences from the Norwegian armed forces," in IFIP Working Conference on The Practice of Enterprise Modeling, Berlin, 2011.

[25] L. Urbaczewski and S. Mrdalj, "A Comparison of Enterprise Architecture Frameworks," Issues in Information Systems, vol. 7, no. 2, pp. 18-23, 2006.

\section{Authors' Profiles}

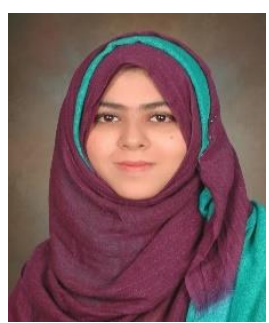

Hareem Qazi is currently doing Masters in the field of computer science from Institute of Business Administration (IBA), Karachi, Pakistan She recieved Bachelors degree in the field of computer science from IBA in 2016.

She has worked as an IT internee in Agility Logistics (Pvt) Ltd. and Children Cancer Hospital $(\mathrm{CCH})$, Pakistan. Her area of research is data mining, text mining and knowledge management.

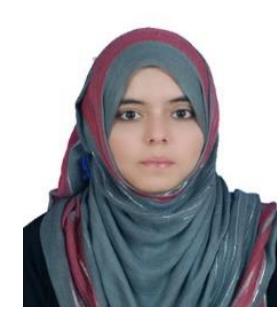

Zainab Javed has done bachelor's in software engineering from NED University of Engineering and Technology, Karachi, Pakistan. Currently, she is enrolled in Master's Program of Institute of Business Administration (IBA), Karachi, in the field of computer science.

She has worked as an Assistant Manager at K-Electric in SAP department. Previously, she did her internship at Sui-Southern Gas Company (SSGC) to gain an insight of the IT architecture of an organization. 


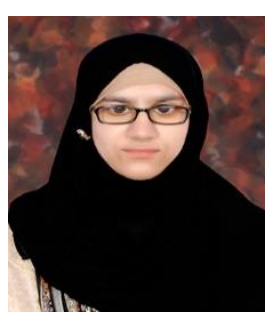

Sameen Majid is pursuing her Masters in the field of computer science from the Institute of Business Administration (IBA), Karachi, Pakistan. Sameen previously completed her Bachelors in computer science from IBA.

She did her internship in Engro and AKUH and worked as an Executive Officer II in Feroze Textiles as a Data Analyst. Her research area is MIS and Business Intelligence.

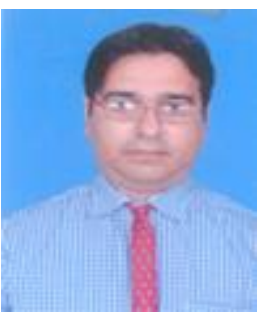

Waqas Mahmood has done MS in Economics and Finance from IoBM (CBM), Karachi in 2012. Prior to that Waqas did MS in Software Project Management from NUCES (FAST) in 2010. Moreover, he holds Masters of Engineering (M.Engg) degree from Hamdard University and M.E degree from NED. He completed his BS (Engg) from Sir Syed University of Engineering \& Technology in 1998 From January 2008 till present he has been working as a Joint Director in State Bank of Pakistan. He has been a part of IBA's visiting faculty from past 10 years.

How to cite this paper: Hareem Qazi, Zainab Javed, Sameen Majid, Waqas Mahmood, "A Detailed Examination of the Enterprise Architecture Frameworks Being Implemented in Pakistan", International Journal of Modern Education and Computer Science(IJMECS), Vol.11, No.9, pp. 44-53, 2019.DOI: 10.5815/ijmecs.2019.09.05 